\title{
Aneurysmal bone cyst of the metatarsal: A case report
}

\author{
JIANGYINZI SHANG ${ }^{1,2^{*}}$, RUNSHENG GUO ${ }^{1,2^{*}}$, PING ZHAN ${ }^{1,2}$,

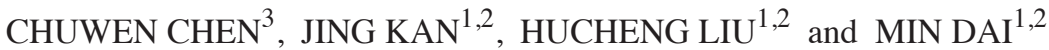 \\ ${ }^{1}$ Department of Orthopedics, The First Affiliated Hospital of Nanchang University; \\ ${ }^{2}$ Artificial Joints Engineering and Technology Research Center of Jiangxi Province; \\ ${ }^{3}$ Nanchang University, Nanchang, Jiangxi 330006 P.R. China
}

Received January 14, 2015; Accepted February 19, 2016

DOI: $10.3892 / \mathrm{ol} .2016 .5007$

\begin{abstract}
An aneurysmal bone cyst (ABC) is a rare, non-neoplastic, destructive, hemorrhagic and expansile lesion accounting for $1 \%$ of all bone tumors. This type of lesion predominantly affects long bones and vertebrae. ABC of the metatarsal is rare and only a few cases have been reported in the literature to date. The present study reports a rare case of $\mathrm{ABC}$ of the third metatarsal occurring in a 27 -year-old male patient, who presented with repeated foot swelling that had lasted for $\sim 1$ year. Other clinical manifestations included limping, multiple lumps (defined as masses on or below the skin, as detected by imageological diagnosis) and progressively increasing local pain in his right foot. Magnetic resonance imaging of the right metatarsal revealed a segmented, expansile, multiseptated lesion with fluid-fluid levels. An en bloc resection was performed and the defect was replaced with a tricortical iliac autograft. Pathological analysis of the resected tissue suggested $\mathrm{ABC}$. The present study aims to describe a case of $\mathrm{ABC}$ of the metatarsal, a condition that often poses a diagnostic challenge, and to underline the importance of radiological and histological examinations for the accuracy of that diagnosis.
\end{abstract}

\section{Introduction}

An aneurysmal bone cyst (ABC) is a benign, locally destructive lesion of the bone, occurring as a primary bone cyst in $\sim 79 \%$ of cases, or as a secondary lesion arising from other osseous conditions in $\sim 20 \%$ of cases (1-3). The peak age of onset is $<20$ years, and $\sim 95 \%$ of cases have been reported to occur in the first 3 decades of life (4). ABC accounts for

Correspondence to: Dr Hucheng Liu or Dr Min Dai, Department of Orthopedics, The First Affiliated Hospital of Nanchang University, 17 Yong Wai Zheng, Nanchang, Jiangxi 330006, P.R. China

E-mail: liuhch2008@126.com

E-mail: daimin@medmail.com.cn

*Contributed equally

Key words: aneurysmal bone cyst, metatarsal, iliac crest bone graft $\sim 1 \%$ of all bone tumors $(5,6)$. Any bone may be affected by $\mathrm{ABC}$; however, these lesions predominantly manifest in the metaphysis of long bones (65\%), the pelvis (12\%) and the arch of the spine (12\%) (7). The differential diagnosis associated with this lesion includes giant cell tumor (GCT), giant cell reparative granuloma (GCRG) and Brown tumor arising from hyperparathyroidism (8-10). Treatment options for patients with $\mathrm{ABC}$ include autogenous bone grafting, cementation or resection of the lesion (11). The present study reports a case of $\mathrm{ABC}$ localized to the metatarsal, a considerably rare presentation of which only a few cases have been reported to date (12).

\section{Case report}

A 27-year-old male patient with ABC presented to the First Affiliated Hospital of Nanchang University (Nanchang, China) in December 2014 with a history of foot swelling for $\sim 1$ year. Other symptoms included limping and progressively increasing local pain in his right foot. The patient and his family initially noticed the swelling following the onset of pain caused by a mild sprain. Thereafter, the patient reduced his activities in an effort to alleviate the pain. He had no history of trauma, fever or general disease.

Physical examination revealed a tender, densely indurated, immobile mass, which measured $\sim 6 \mathrm{~cm}$ in diameter and was localized to the right forefoot. Standard foot radiographs revealed an expansive, lytic and proliferative lesion localized to the third metatarsal (Fig. 1A). Magnetic resonance imaging (MRI) showed that the tumor exhibited a high signal intensity on T2-weighted images (Fig. 1B). The patient underwent operation for wide excision of the lesion, including the whole third toe, and an autogenous iliac crest bone graft, along with double-plate fixation affixed to the second and forth toes (Fig. 2). Informed consent was obtained from the patient for the publication of the data regarding the diagnosis and treatment.

The gross appearance of the removed tissue was a soft, dusty-red tissue mass measuring $5.5 \times 5 \times 2.5 \mathrm{~cm}$. Histopathological examination was subsequently conducted. The microscopic appearance of the resected tissue was capsule-shaped, exhibiting large amounts of dilatation and congestion of the associated small blood vessels, osteoblast proliferation (as indicated by the blue particles 

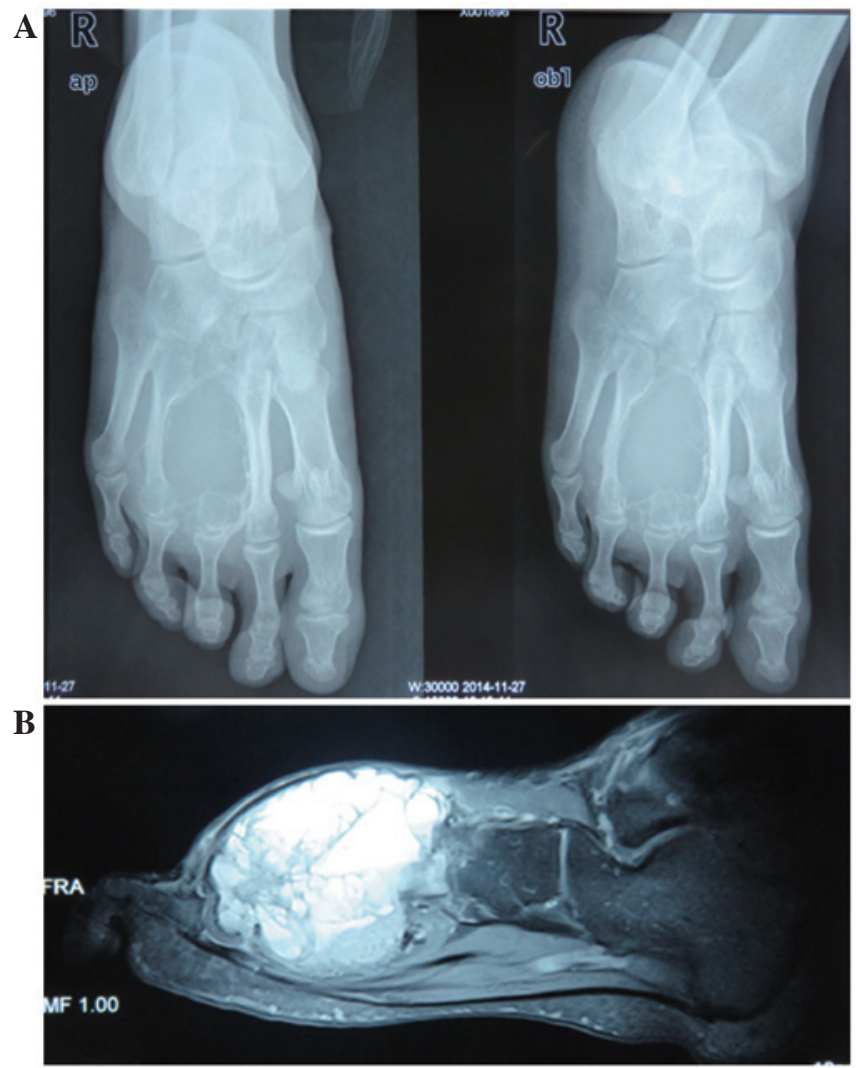

Figure 1. (A) Radiograph showing a lytic lesion in the entire third metatarsal, leaving the cortex as a thin shell with a 'finger in a balloon' appearance. (B) T2-weighted magnetic resonance imaging sequence showing deformity of the involved metatarsal bone with fluid-fluid levels.

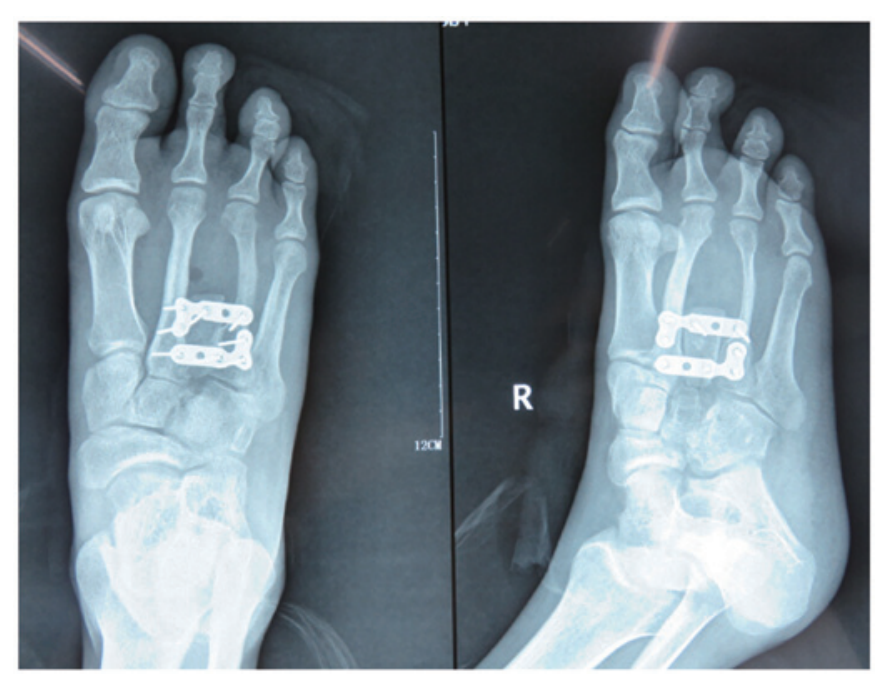

Figure 2. Intraoperative radiographs of the lesion following repair and stabilization using double-plate fixation.

corresponding to osteoprogenitor cells that were detected by hematoxylin-eosin staining), fibrous connective tissue and multinucleated giant cell proliferation, with reactive hyperplasia and trabecular bone tissue (Fig. 3). A final diagnosis of $\mathrm{ABC}$ was established based on the collective clinical information. The treatment was successful, as no further treatment was required during subsequent follow-ups and the patient remains healthy at present.
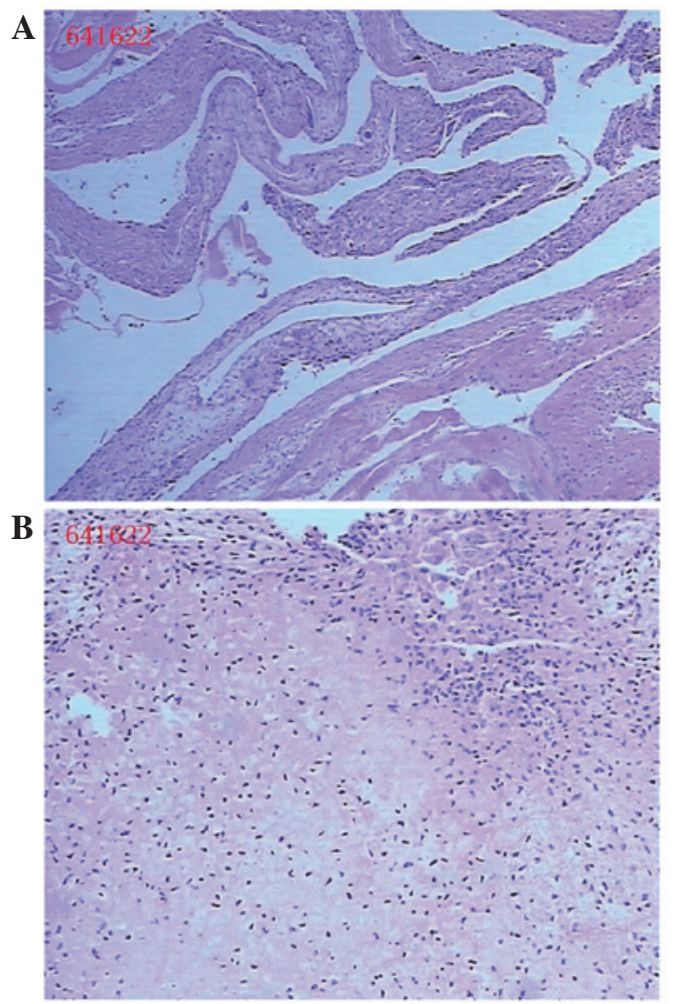

Figure 3. Histological examination images. (A) Section includes lamellae surrounded with congestion of small blood vessels, and blood-filled cystic spaces separated by fibrous septae (HE staining; original magnification, x40) (B) Multiply of osteoblast proliferation, fibrous connective tissue and multinucleated giant cell proliferation (HE staining; original magnification, x100). HE, hematoxylin-eosin.

\section{Discussion}

ABCs account for $\sim 1 \%$ of all primary bone lesions that are sampled for biopsy (13). While the precise pathogenesis of $\mathrm{ABC}$ is unclear, the most widely accepted pathogenic mechanism of $\mathrm{ABC}$ involves local circulatory disturbance, which results in an increase in venous pressure and the development of enlarged and dilated vascular components within the affected bone (2). The differentiation among $\mathrm{ABC}$ and other giant cell-containing tumors of the bone, such as GCT, GCRG and Brown tumor, is crucial (13). GCT is composed of mononuclear and osteoclast-like multinucleated giant cells, which have the potential to be locally aggressive $(14,15)$. In GCT, the tumor is always eccentrically located in the epiphysis and metaphysis of the bone, and exhibits lytic expansion (16). GCRG is a rare, benign, intraosseous reactive lesion, histologically characterized by a predominance of giant and mononuclear cells in areas of hemorrhage (17). Brown tumors have been reported to occur in $1.5-1.7 \%$ of patients with chronic renal deficiency and to have a considerably more lobulated architectural growth pattern; at differential diagnosis, hyperparathyroidism can be ruled out on the basis of serum calcium, parathyroid and phosphorus hormone levels $(18,19)$. ABC, on the other hand, is known to be histologically composed of blood-filled cystic spaces separated by fibrous septae (20).

Computed tomography and MRI scans may be helpful in the diagnosis of ABC, since T2-weighted MRI could detect 
a deformity in the involved metatarsal bone as a segmented, expansile, multiseptated lesion with a large quantity of fluid present (21).

Surgical removal is considered the optimal treatment option for ABC. The lesion is removed by intralesional curettage through a wide cortical window, and allograft bone grafting may be used for replacement of bone defects (22). Embolotherapy has also been successfully used for the treatment of ABCs (23). However, patients must be informed that $\mathrm{ABC}$ has a high recurrence rate (24), so that any recurrence or malignant transformation can be detected as early as possible.

In summary, $\mathrm{ABC}$ is a destructive, hemorrhagic and tumor-like lesion occurring predominantly in teenaged patients. Radiographs and MRI scans can often confirm the diagnosis of $\mathrm{ABC}$; however, accurate histological evaluation is imperative for diagnosis. Embolotherapy and replacement of bone defects with a tricortical autograft are considered safe procedures with minimal recurrence risk (25). The present study described a rare case of a $\mathrm{ABC}$ in the metatarsal and highlighted the importance of radiological and histological examinations for the accuracy of such diagnosis.

\section{References}

1. Jaffe HL and Lichtenstein L: Solitary unicameral bone cyst with emphasis on the roentgen picture, the pathologic appearance and the pathogenesis. Arch Surg 44: 1004 -11025, 1942.

2. Cottalorda J and Bourelle S: Modern concepts of primary aneurismal bone cyst. Arch Orthop Trauma Surg 127: 105-114, 2007.

3. Lichtenstein L: Aneurysmal bone cyst: A pathological entity commonly mistaken for giant cell tumor and occasionally for hemangioma and osteogenic sarcoma. Cancer 3: 279-289, 1950.

4. Singh DK, Singh N and Pant MC: Aneurysmal bone cyst: An unusual presentation of back pain. Asian J Neurosurg 9: 105-107, 2014.

5. Hakim DN, Pelly T, Kulendran M and Caris JA: Benign tumours of the bone: A review. J Bone Oncol 4: 37-41, 2015.

6. Bonakdarpour A, Levy WM and Aegerter E: Primary and secondary aneurysmal bone cysts: A radiological study of 75 cases. Radiology 126: 75-83, 1978.

7. Campanacci M, Capanna R and Picci P: Unicameral and aneurysmal bone cysts. Clin Orthop Relat Res 204: 25-36, 1986.

8. Barnhart MD: Malignant transformation of an aneurysmal bone cyst in a dog. Vet Surg 31: 519-524, 2002.

9. Hsu CS, Hentz VR and Yao J: Tumours of the hand. Lancet Oncol 8: 157-166, 2007.
10. Saito T, Oda Y, Kawaguchi K, Tanaka K, Matsuda S, Sakamoto A, Iwamoto Y and Tsuneyoshi M: Five-year evolution of a telangiectatic osteosarcoma initially managed as an aneurysmal bone cyst. Skeletal Radiol 34: 290-2941, 2005.

11. Ozaki T, Hillmann A, Lindner N and Winkelmann W: Aneurysmal bone cysts in children. J Cancer Res Clin Oncol 122: 767-769, 1996.

12. Vergel De Dios AM, Bond JR, Shives TC, McLeod RA and Unni KK: Aneurysmal bone cyst. A clinicopathologic study of 238 cases. Cancer 69: 2921-2931, 1992.

13. Freiberg A, Loder R, Heidelberger $\mathrm{K}$ and Hensinger RN: Aneurysmal bone cysts in young children. J Pediatr Orthop 14: 86-91, 1994.

14. Foo LF and Raby N: Tumours and tumour-like lesions in the foot and ankle. Clin Radiol 60: 308-3332, 2005.

15. Ratner V and Dorfman HD: Giant-cell reparative granuloma of the hand and foot bones. Clin Orthop Relat Res 260: 251-258, 1990.

16. Futamura N, Urakawa H, Tsukushi S, Arai E, Kozawa E, Ishiguro $\mathrm{N}$ and Nishida Y: Giant cell tumor of bone arising in long bones possibly originates from the metaphyseal region. Oncol Lett 11: 2629-2634, 2016.

17. Cook DL, Rosenthal DC and Shikoff MD: Giant cell reparative granuloma of the middle phalanx of the foot: A review and case report. J Foot Ankle Surg 47: 589-593, 2008.

18. Hanna BG, Donthineni R, Majid K, Parekh S, Shin JS and Lackman RD: Leg mass in a 61-year-old man. Clin Orthop Relat Res 406: 298-307, 2003

19. Brindley GW, Greene JF Jr and Frankel LS: Case reports: Malignant transformation of aneurysmal bone cysts. Clin Orthop Rel Res 438: 282-287, 2005.

20. Gibbs PC Jr, Hefele MC, Peabody TD, Montag AG, Aithal V and Simon MA: Aneurysmal bone cyst of the extremities. Factors related to local recurrence after curettage with a high-speed burr. J Bone Joint Surg Am 81: 1671-1678, 1999.

21. Iltar S, Alemdaroğlu KB, Karalezli N, Irgit K, Caydere M and Aydoğan NH: A case of an aneurysmal bone cyst of a metatarsal: Review of the differential diagnosis and treatment options. J Foot Ankle Surg 48: 74-79, 2009.

22. Boubbou M, Atarraf K, Chater L, Afifi A and Tizniti S: Aneurysmal bone cyst primary-about eight pediatric cases: Radiological aspects and review of the literature. Pan Afr Med J 15: 111, 2013

23. Rastogi S, Varshney MK, Trikha V, Khan SA, Choudhury B and Safaya R: Treatment of aneurysmal bone cysts with percutaneous sclerotherapy using polidocanol. A review of 72 cases with long-term follow-up. J Bone Joint Surg Br 88: 1212-1216, 2006.

24. Cugati G, Pande A, Jain PK, Symss NP, Ramamurthi R and Vasudevan CM: Aneurysmal bone cyst of the lumbar spine. Asian J Neurosurg 10: 216-218, 2015.

25. de Kleuver M, van der Heul RO and Veraart BE: Aneurysmal bone cyst of the spine: 31 cases and the importance of the surgical approach. J Pediatr Orthop B 7: 286-292, 1998. 